\title{
AUTISMO E SEXUALIDADE
}

AUTISM AND SEXUALITY

AUTISMO Y SEXUALIDAD

Lucia Maria de Lima Mello*

\begin{abstract}
RESUMO
Este artigo percorre alguns conceitos básicos da psicanálise sobre autismo e sexualidade, servindo-se de alguns fragmentos dos testemunhos de quatro sujeitos que, em relatos biográficos únicos, abordam esses dois conceitos. Quatro perspectivas diferentes sobre percursos diversos da experiência infantil com base no real e que abordam uma categoria, baseada no silêncio, no sofrimento da extrema angústia, esforço pessoal na construção de um Outro sob medida.
\end{abstract}

Palavras-chave: Autismo. Sexualidade. Psicanálise.

\section{ABSTRACT}

This article deals with a few basic concepts from psychoanalysis regarding autism and sexuality using fragments of testimonies from four subjects who in isolated biographic reports, address to these two concepts. Four different perspectives on diverse courses of the child experience based on the real and which approach a category based on the silence, in the suffering of the extreme anguish, a personal effort in the creation of a tailored Other.

Keywords: Autism. Sexuality. Psychoanalysis.

\section{RESUMEN}

Este artículo analiza algunos conceptos básicos del psicoanálisis sobre el autismo y la sexualidad utilizando algunos fragmentos de los testimonios de cuatro sujetos que, en informes biográficos únicos, abordan estos dos conceptos. Cuatro perspectivas diferentes sobre distintos caminos, desde la experiencia de la infancia basados en la realidad y que abordan una categoría, basada en el silencio, el sufrimiento de la angustia extrema, el esfuerzo personal en la construcción de otro a la medida.

Palabras clave: Autismo. Sexualidad. Psicoanálisis.

\footnotetext{
* Mestra em Psicologia pela Pontifícia Universidade Católica de Minas Gerais (PUC Minas), professora adjunta III no Curso de Psicologia da PUC Minas, supervisora clínica, professora no Curso de Especialização Latu Sensu Abordagem Psicanalítica do Autismo e Conexões, IEC PUC Minas, membro da Escola Brasileira de Psicanálise e da Associação Mundial de Psicanálise, psicanalista, psicóloga. E-mail: delimaebp@gmail.com.
} 


\section{INTRODUÇÃO}

(ک Os autistas ensinam que os sujeitos podem ser simultaneamente mergulhados na linguagem e absolutamente silenciosos, sem nenhum 'dizer'” (Laurent, 2012, p. 11a). "Visar o singular consiste em pensar um sujeito como subversão de uma categoria e não como ilustração" (Laurent, 2012, p. 9b).

Duas frases, colhidas em uma entrevista de Laurent, servem para orientar uma pesquisa sobre a questão delicada da sexualidade considerada em alguns sujeitos autistas. Os relatos autobiográficos, que, felizmente, são cada vez mais frequentes, contribuem e alimentam as pesquisas clínicas, evidenciando a curiosa subversão de uma categoria, visto que apenas um sujeito poderá ensinar uma experiência única aos familiares e profissionais que participam de seu tratamento. $\mathrm{O}$ mergulho nas particularidades de um mundo misterioso ensina o que foi para cada um elaborar uma existência tecida com letras, códigos decorrentes da construção de um campo de linguagem próprio, um Outro sob medida e o esforço que fazem no sentido de comunicar conexôes incomuns ou muito próximas do sentido estético encontrado na poesia, literatura, pintura, música.

Quanto à sexualidade, é situada pela psicanálise desde o início da pesquisa freudiana até as contribuições de Lacan como um campo muito amplo de interesses, investimentos-desinvestimentos libidinais diversos muito além do ato sexual. Inicialmente decorrente dos traços marcados nas experiências de satisfação e dor, tecidos em torno de um vazio, do consentimento na assimilação expulsão desses traços. A relação com a linguagem, essencial para o humano, instaura-se em torno do desamparo primitivo, subvertendo a natureza apartando-o do abrigo instintual e também de início, confrontado a uma satisfação estranha, paradoxal, que a psicanálise nomeia de desejo e gozo. O "trauma da linguagem" decorre da cessão do objeto de gozo primordial, permitindo localizá-lo fora do corpo" (Maleval, 2017, p. 106a). O sujeito se separa do gozo vocal e inicia o processo de identificação primordial ao Outro. A partir desse trauma, a sexualidade dependerá tanto dos traços, marcas, letras de uma experiência quanto do que se inscreve diretamente nos corpos, em um espaço aparentemente exterior, enigmática desde os primeiros encontros com o outro humano, estendendo-se até o campo da sociedade, da cultura.

A linguagem implica uma causalidade lógica diversa da aprendizagem formal, visto que precede a vinda do sujeito ao mundo e prossegue para além de sua morte. "Para ter o sentimento de vida é preciso nascer uma segunda vez, para o desejo [.. . ] com as palavras que são incrustadas em nossos corpos sem nos apercebemos que elas nos concernem" (Leguil, 2019, p. 61). 
O balbucio inicial dos bebês acarreta deleite com a sonoridade das palavras, mas, ao mesmo tempo, afeta-o com satisfaçôes paradoxais que implicam o desprazer, o circuito das demandas a circulação dos objetos pulsionais no difícil intercâmbio social entre o sujeito e o Outro. A satisfação de uma sonoridade solitária, autoerótica, será perturbada, se possível permutada, a partir do espelho imaginário da criação de um corpo, da satisfação sempre incompleta com esse corpo em permanente mudança e suas funções muitas vezes desconhecidas.

A angústia surge diante do desejo e opera como um termo intermediário entre o gozo e o desejo. Lacan assinala decisivamente as cinco etapas da constituição do objeto na relação sujeito ao Outro, o objeto oral, anal, a etapa fálica, etapa escópica e a voz como demanda do Outro (Lacan, 2004, p. 336). Tempos de confrontação incessante ao real, nos quais as tentativas de tratamento pelo simbólico, imaginário e o próprio real são continuamente praticadas pelas crianças. As teorias sexuais infantis, que, antes de serem teorias psicanalíticas, são construções subjetivas que têm origem precocemente nos componentes da pulsão sexual, comparecem como trabalho singular na organização do infantil e se evidenciam nos corpos, nos atos, sintomas, fantasias, sobretudo nas angústias, medos, pânico.

O sexo, portanto, chega à criança de diversas maneiras, nas experiências das zonas erógenas de seu corpo, traumaticamente pela presença e ausência das palavras e gozo, por acaso, pela contingência de um encontro, do que surge como sintomas, falicamente, quando dispóem de significantes para organizar sua experiência, teoricamente, quando podem ter acesso às informações que vêm do Outro (Drummond, 2004, p. 29).

As ligações, laços amorosos ou de ódio entre sujeitos, estendem-se até implicar causas sociais, científicas, políticas, religiosas, conexões institucionais, associações, interesses particulares exclusivos, filiações, alianças, separações, constituem "um espaço onde cada sujeito pode dar curso à expressão mais íntima de sua vida subjetiva, com ou sem parceiro, em uma construção que pode equivaler a uma obra a dois ou 'solo'" (Fajnwaks, 2019, p. 7).

Nesse tema não se podem desconsiderar três pressupostos básicos: o primeiro deles, o vasto campo da sexualidade humana se inscreve a cada época, de modo diverso, nas sociedades, na civilização, na história. Em segundo lugar, a sexualidade biológica não é tão natural quanto parece, visto que, para os humanos, por sofrer incidência dos laços sociais, da cultura, dos registros de vida e morte, a linguagem desgarrou-se das coordenadas naturais, conforme assinalado ainda por diversas epistemes. Para a psicanálise, a anatomia não é um 
destino, e a escolha sexual encontra-se para cada um como decisão subjetiva. Em terceiro, o sexo é um dizer.

A psicanálise investiga as pulsões, de vida e morte, forças que se movem a partir de circuitos em torno do objeto, produzindo ressonâncias, conexões entre os sujeitos, os objetos, o meio, sintomas, fantasias, na fronteira entre o corpo e o campo da palavra. Apresentam-se tanto como formas diversas de atividade, passividade ou na voz reflexiva, satisfações desconhecidas que atravessam modos de vida, alimentação, sobrevivência, submetidas ou não à estrutura gramatical da linguagem. A clínica demonstra pelos acontecimentos de corpo, as atuações, passagens ao ato, os atos imotivados, sem sentido, repetições, compulsões, adicções, a força e, por vezes, o silêncio desses modos de satisfação. A sexualidade de um ser falante permeia e demonstra a disjunção-conjunção fundante dos enlaçamentos diversos, registros inscritos em três dimensões: real, simbólico e imaginário.

Dividido entre um gozo fálico e um gozo sem nome, o sujeito promove, pela via dos semblantes, a prática sempre renovada da ilusão de recobrir o impossível de dizer e escrever a relação sexual, diante também do problema que constitui a inadequação entre simbólico e real. A partir do limite da palavra demonstrada por Lacan em seu último ensino, a falta irremediável de um significante no campo do Outro, a dimensão real do inconsciente encontrará no autismo, curiosamente, sua melhor expressão.

\section{AS QUESTÕES DOS AUTISTAS}

É preciso considerar a extrema diversidade da estrutura autística, que inclui os sujeitos que não falam, dos que empregam ecolalias ou verborreia incessantes e sem sentido, dos que pensam em imagens, que calculam, produzem ou utilizam da música, pintura, até aqueles que, apoiados nos objetos, nos duplos, nas bordas, nas ilhas de competência, consentem em superar a angústia avassaladora que representa ceder um pouco, reduzir um excesso do objeto de gozo inicial e mergulhar no banho de linguagem proposto por Lacan.

O sujeito autista ensina sobre o real. Os resultados da pesquisa iniciada na década de 1950 pelos Lefort, e comunicada em 1980, a partir do atendimento às crianças que apresentavam o autismo infantil primário, precoce, grave trazem essa descoberta, assim como outras verificações preciosas para a psicanálise e atestada pelas diversas autobiografias consultadas. Essa predominância do real na estrutura decorre da forclusão do furo, "da ausência da Bejahung, onde o sujeito permanece frente a um significante que não significa nada, salvo o ser de 
real antes de toda sexuação" (Lefort, 2017, p. 52). Essa modalidade de forclusão difere daquela apresentada pela psicose, que, nessa estrutura, é situada no campo do Outro. A forclusão do furo não permite fazer um menos no real. "O mundo cheio, pleno, não permitiria incluir ou dar lugar ao simbólico ou a falta” (Laurent, 2013, p. 82). No autismo, é apresentada tanto nas automutilações que surgem, por vezes, como tentativas de esvaziamento do excesso de gozo, um excesso de excitação, quanto de inscrever um menos no real, pela música, repetições, jogos, deslocamentos, palavras. Os testemunhos da intolerância ao furo são muito numerosos, tanto na clínica quanto nas biografias, prossegue o autor.

A dissociação entre voz e linguagem está no princípio do autismo, o que é verificado em todos os graus, níveis diversos, evidenciada na dificuldade da posição enunciativa, visto que a linguagem não é investida pelo gozo vocal. A não extração do objeto pulsional impede a criação de um circuito e, consequentemente, impede o enfrentamento da angústia, que, sem mediação, recai sobre o sujeito. Essa defasagem é descrita por Williams, entre outros autistas, quando ensina em sua autobiografia:

"Não repete tudo que eu digo" - repreendia a voz.

Levava uma bofetada. Eu não fazia a mínima ideia do que se esperava de mim.

Durante os meus primeiros três anos e meio de vida esta foi toda a minha linguagem, acrescida das entonaçôes e das inflexôes vocais daqueles que eu pensava que faziam parte do "mundo". O mundo se mostrava impaciente, importuno, duro e implacável. "Com o passar do tempo, aprendi a lhe responder com lágrimas e gritos, ou pela indiferença ou fuga" (Williams, 2012, pp. 28-29a).

Os testemunhos biográficos percorrem escolhas singulares, casamentos com parceiros de sexo diferente ou mesmo sexo, opção pela posição celibatária, parceiros sexuais aleatórios e ligação libidinal exclusiva com a ciência, o cinema, a música, a literatura, matemática, física. $\mathrm{O}$ espectro das escolhas é tão amplo, diverso, particular como de outros seres falantes. Apenas há de se considerar especificidades da estrutura de um sujeito que necessita da imutabilidade, repetição, iteração, de modificações mínimas no ambiente, para se manter organizado e que trabalha incessantemente, por vezes em silêncio, para compor uma existência.

Esse trabalho requer o apoio de recursos auxiliares, escolhidos e sinalizados pelo próprio sujeito como a construção de uma borda, que pode ser flexível, ampliar ou retrair segundo as circunstâncias, o uso dos objetos sempre dinâmicos, 
que podem funcionar como captadores de libido, reguladores de gozo, duplo protetor, criado pelo sujeito com o qual pode estabelecer relações ambivalentes, as ilhas de competência configuradas geralmente como "a apropriação de um saber totalizante num domínio restrito" (Maleval, 2017, p. 200b).

\section{QUATRO SUBVERSÕES DE UMA CATEGORIA}

A biografia Vida animada, que inspirou um documentário e filme, escrita por Suskind (2009) sobre seu filho, traz o extenso relato do recurso escolhido por Owen, que o orientou desde os 6 anos: os filmes da Disney, os diálogos entre os personagens, as músicas, repetidos e usados em diversos momentos da vida, para encontrar sentido no mundo. Desde que "perde sua voz" aos 3 anos, ele se apoia progressivamente nos diálogos, entre outros filmes, da Pequena sereia, descoberta emocionante descrita pelo escritor. $\mathrm{O}$ mundo animado e o real funcionando em planos paralelos e empregados no trânsito do diálogo difícil com as pessoas. Esses planos paralelos curiosamente se entrelaçam à ficção, servindo de suporte para a realidade. Quando na adolescência Owen encontra Emily e iniciam um namoro, ele recorre à Dama e o vagabundo como um roteiro para organizar etapas das perguntas-respostas, nortear seu namoro, sua conduta. Os filmes orientam também o processo criativo de invenção de suas próprias histórias, roteirizam sua autonomia (Suskind, 2009, pp. 325-336).

Owen se vale do duplo cuja utilização compôs preferencialmente a borda protetora, fundamental na compensação à falta da identificação primordial no processo de dar vida ao Outro. Isso lhe permite a saída progressiva do retraimento orientando sua existência em direção ao trabalho criativo. Considerando a falta de conexão entre emoção e pensamento, o Outro de síntese opera uma imitação, tornando-se uma emoção representada franqueando palavras, permitindo falar, por ordem no mundo, mas sua aptidão para representar o vivente não inclui o funcionamento do $S_{1}$. (Maleval, 2017, pp. 50-53c).

Grandin, autora de várias publicações, professora de Ciência Animal na Universidade do Colorado (Estados Unidos), pesquisadora, fornece, em sua autobiografia, ensinamentos interessantes. "O riso incontrolável, as perguntas, o falatório constante, a obsessão por determinados assuntos são características comuns de crianças autistas. Minhas fixações reduziam a excitação e me acalmavam" (Grandin \&Scariano, 1999, p. 42a). Desde criança, ela foi interessada por máquinas e não por gente. Por isso construiu muito cedo sua "máquina de pressão", na qual se instalava com a finalidade de acalmar sua intensa angústia. 
Mesmo agora, depois de ter construído e usado a máquina de pressão, ainda sinto medo dela. A sensação de estar no brete para gado é boa, mas os sentimentos que a ação desperta são às vezes dolorosos. Ainda tenho dificuldades em aceitar meu lado emocional (Grandin \& Scariano, 1099, p. 42).

Esse temor que as emoções despertam determina sua escolha, "é por isso que tenho medo do casamento". "Foi por essa atitude insensível (das pessoas) que me fez desistir da ideia do casamento e me tornar celibatária" (Grandin \& Scariano, 1999, pp. 112-113b).

Uma das contribuições importantes de Grandin em suas pesquisas foi explorar os três estilos de pensamento autísticos, pensamentos em imagens, em padrões, em repetiçôes, que incluem cifras e cálculos, mas não se valem da linguagem comum, e podem incluir máquinas, objetos, fragmentos, compondo o que Laurent considera um circuito pulsional transformado, uma maneira original de regular a vida. Em suma, uma composição que inclui o real (Laurent, 2014, pp. 31-33).

Para Grandin, não se trata da voz, mas do uso do objeto autístico complexo que lhe permite uma identificação. "Ela se regenera ao se fundir com o objeto da falta imaginária” (Maleval, 2017, p. 342d). A regulação do gozo, o controle da agressividade, das emoções é alcançado pela contenção promovida pela máquina, um sujeito completado por um objeto. Essa integração ao objeto prossegue o autor, promove a apropriação do sentimento e animação libidinal do sujeito, que pode construir sua vida a partir das identificações ao animal e à máquina, tema exclusivo de seu trabalho de ensino e pesquisa. A borda protetora permitiu o controle do pânico, da extrema ansiedade, pavor, tensão constante descrita pela autora. A partir desse uso, Grandin desenhou, calculou, projetou equipamentos e instalações para pecuária criando em seguida sua própria empresa, servindo-se de sua capacidade de pensar visualmente.

O livro de Williams, australiana, graduada em Literatura, diz, em testemunho excepcional, de uma vida tecendo o fio condutor, desde a infância, em seu trabalho incessante para lidar com um mundo misterioso além da tarefa que implicou a construção de um Outro sob medida por meio dos duplos, objetos autísticos e ilha de competência. Em três capítulos, relata sua história em meio às sombras, seus laços amorosos atravessados por sensibilidade exacerbada e decididamente marcados pela solidão, traço infantil predominante: "Jamais abracei meus pais, como também eles jamais me abraçaram. Eu não gostava que alguém se aproximasse muito de mim, e não permitia que ninguém me tocasse. Todo contato físico me era penoso e me amedrontava" (Williams, 2012, p. 35b). Em um desses namoros, ela relata: "Não procurávamos espécie alguma 
de ligação mútua, de comprometimento". "O silêncio e a distância afetiva me permitiram também experimentar o prazer do contato afetivo, até que enfim, sem medo de me sentir tocada" (Williams, 2012, p. 255c).

Os recursos suplementares eram, desde cedo, colocados em prática, como na leitura, recorrendo à memorização e ilustrações. "Se bem que eu pudesse ler uma história sem dificuldade, só compreendia seu conteúdo com a ajuda de ilustrações" (Williams, 2012, p. 60d). A música, recurso importante, surgia na condição de gozo autoerótico, visto que Williams era pianista e compositora. Os duplos Carol e Willie eram suportes para sua enunciação e participavam das estratégias para compreender o sentido das frases dos outros.

A autora, no epílogo de seu livro, Resumo da linguagem característica do meu próprio mundo, assinala tópicos que considera essenciais como tentativa de ensino sobre os autistas, esforço excepcional de informação particular sobre uma experiência única.

Por seu turno, uma nova surpresa surge com Tammet, britânico, graduado na The Open University, autor de vários livros, linguista, novelista, poeta, gênio matemático. Nascido em um dia azul, uma de suas autobiografias mais conhecidas, onde descreve, no percurso de sua infância até a vida adulta, a relação particular com os números, que ele considera "dimensão estética de minha sinestesia", cada um deles descrito em sua "personalidade" e que podem ser simpáticos, tímidos, feios, pequenos, ou associados à imensidão como o número 9. Sua capacidade para ver letras e números em cores, texturas e movimentos. Faz parte de seu trabalho como calculista prodigioso. "Quando calculo nunca escrevo nada porque sempre posso manejar as operações em minha cabeça. Se vejo um número que experimento como especialmente atrativo sinto um calafrio de excitação e prazer" (Tammet, 2006, pp. 7-8a).

Quando bebê, não respondia aos cuidados maternos. Sua única manifestação era o choro contínuo, sem associação com doenças e mal-estar físicos. Apenas os movimentos repetitivos pareciam acalmá-lo. Foi um menino mal-humorado, doente, chorão, que batia a cabeça nas paredes, ritmadamente, até provocar feridas. Era solitário, sensível aos ruídos e não interagia com outras crianças, porque, além da timidez, não tinha noção do jogo como atividade compartilhada, mantendo-se absorto, distante, protegido em seu mundo. As crises epilépticas, iniciadas aos 4 anos e descritas como "golpeado por um raio", título de um dos seus tópicos, a despeito dos recursos limitados, receberam bom prognóstico e medicação adequada.

$\mathrm{Na}$ escola primária, a sensação de sossego e prazer foi alcançada com o uso da matemática, ao lado do que considera suas obsessōes e coleções diversas. Aos 
18 anos, respondeu a um anúncio de recrutamento destinado aos jovens de baixa renda para trabalho de ensino de inglês no exterior. A experiência de um ano em Kaunas, na Lituânia, implicou outra dimensão do estranho que sempre se sentira, através dos costumes de outra sociedade, outro idioma. A decisão de viver com um companheiro, ocorrida no retorno para a Inglaterra, ratifica uma escolha feita aos 11 anos que permanecera em silêncio. Anos mais tarde, Tammet se casou com outro namorado, mas é curioso ressaltar, no capítulo de sua sexualidade, as palavras que emprega para descrever o número pi, número irracional e infinito, um dos tópicos de sua autobiografia. Ele participou de um evento no Museu Histórico de Ciências, em seu país, em 2004, que resultou em reconhecimento mundial. Recitou, durante cinco horas, até alcançar 22 mil dígitos, o cálculo de Pi, ultrapassando o recorde europeu. Quando indagado sobre a importância desse recorde, Tammet respondeu: "O pi é algo belo e único. Igual à Mona Lisa ou uma sinfonia de Mozart. Pi é a razão mesma que me faz amá-lo" (Tammet, 2006, p. 116b).

Tammet se mostrou absorvido precocemente por repetições de padrões numéricos, cálculos com associações visuais poéticas, posteriormente acrescida pelo estudo de novos idiomas, revelando-se um linguista ímpar, demonstrando sua excepcional capacidade de captação do gozo pela ilha de competência, o que resultou na criação de um Outro de síntese ampliando, com sua experiência, os limites do chamado espectro autístico.

Owen, Grandin e Tammet contaram com o apoio e compreensão de seus familiares no seu processo de tratamento e construção de uma existência específica. Na autobiografia de Tammet, é surpreendente verificar o quanto uma família numerosa de operários ingleses acolhe e respeita a diferença de um de seus filhos, contribuindo decisivamente para seu trabalho do despertar de seu talento e mudanças substanciais. Williams encontra acolhida preferencialmente com os avós, vizinhos, professores de escolas públicas. A diversidade das famílias é surpreendente, corroborando o quanto o sujeito, em qualquer estrutura, pode fazer uso das contingências, dos acontecimentos imprevistos, mesmo em situaçóes extremas como dos autistas que inicialmente não reagem a sinais afetivos e evitam os equívocos da linguagem.

Para a psicanálise, o autismo constitui um campo de pesquisa sempre renovado, que teve início com o termo forjado por Bleuler, no início do século XX, para descrever um estado de retraimento grave. Prossegue, na década de 1940, com os trabalhos de Kanner, Asperger, Bettelheim, Klein. Rosine e Lefort inauguram, com a contribuição de Lacan, outra perspectiva do estudo da criança no discurso analítico, com base na ênfase conferida ao estatuto do real. 
A clínica dos autistas investigada pela psicanálise tem demonstrado que o sujeito pode se inserir no mundo por meio de poucas palavras e criar, com peças avulsas, um circuito absolutamente original. As questóes propostas pelo nascimento do Outro ampliarão possibilidades do trabalho com os sintomas contemporâneos, além de modificar o conceito de inconsciente. Lacan demonstrará, por meio da falta irremediável de um significante no campo do Outro, a existência de tipos diferentes de gozo, a impossibilidade lógica de significar a relação sexual.

A sexualidade, por sua vez, constitui um campo vasto das relações humanas que compreende dimensões biológicas, sociais, históricas, éticas, culturais, políticas, subjetivas. Acarreta um problema central, porque, contrariamente ao que ocorre com os animais para os quais um programa instintual obedece às leis da natureza, a sexualidade humana precisa dos registros imaginário, simbólico e real para se realizar. Realização marcada pelo mal-entendido, a falta, por desejos insatisfeitos e impossíveis, pelo gozo desmedido e excessivo, pela discordância entre saber e ser.

Por não falar, o real implica uma primazia da escrita sobre a palavra, questão presente no testemunho dos autistas que ensinam a ler, de outro modo, a extrema solidão humana. 


\section{REFERENNCIAS}

Drummond, C. (2004). Ensaio: diferença sexual e inconsciente. In Papéis de psicanálise. (p. 29). Belo Horizonte: IPSM.MG.

Fajnwaks, F. (2019). Tous mariés! La Cause du Désir, 101, 7.

Grandin, T., \& Scariano, M. (1999). Uma menina estranha. São Paulo: Cia. das Letras.

Lacan, J. (2004). Le séminaire, livre X, L’angoisse. Paris: Seuil.

Laurent, É. (2012, octubre). En ligne avec Éric Laurent. La Cause du Désir, 89, $9-11$.

Laurent, É. (2013). La batalla del autismo. Buenos Aire: Navarin.

Laurent, É. (2014). Los autismos en la actualidad. In J.-A. Miller, E. Laurent, J.C. Maleval, F. Schejtman, S.E. Tendlarz, Estudios sobre el autismo. Buenos Aires: Diva.

Lefort, R. (2017). A distinção do autismo. Belo Horizonte: Relicário.

Leguil, C. (2019). L’inconscient et le sentiment de la vie. Mental, 40, 61.

Maleval, J. C. (2017). O autista e sua voz. São Paulo: Blucher.

Suskind, R. (2009). Vida animada. Rio de Janeiro: Objetiva.

Tammet, D. (2006). Nascido em um dia azul. Rio de Janeiro: Intrínseca.

Tammet, D. (2017). Chaque mot est un oiseau qui l'on apprend à chanter. Paris: Les Arènes.

Williams, D. (2012). Meu mundo misterioso. Brasília: Thesaurus. 